\title{
Kinematic Motion Analysis and Structural Analysis of Bellcrank Structures Using FEM
}

\author{
Byeong-Sam Kim ${ }^{1}$, Kyoungwoo Park ${ }^{2}$ \\ ${ }^{1}$ Department of Automotive engineering, Hoseo University, Asan-City, Korea; ${ }^{2}$ Department of Mechanical engineering, Hoseo Uni- \\ versity, Asan-City, Korea. \\ Email:kbs@hoseo.edu
}

Received June, 2013

\begin{abstract}
The results of kinematic motion analysis were used for the structural analysis based on data that the load applied to each part. The problem of the fatigue strength estimation of materials or components containing natural defects, inclusions or in homogeneities is of great importance for both a scientifically or industrial point of view. Fatigue behavior in components is often affected by the presence of residual stresses introduced by processes such as actuator system. Analysis can provide the estimation of the crack growth curves with sufficient accuracy, even in case of complicated bell crank structures which are crucial for preserving aileron integrity and which participate in transfer of load. Probability of crack detection or any other damage detection is a result of many factors. An endurance life prediction of bell crank is used finite element analyses. Endurance test data for slim test specimens were compared with the predicted fatigue life for verification.
\end{abstract}

Keywords: Kinematic Motion Analysis; Fatigue Life Analysis; FEM; Bell Crank System; Structural Analysis

\section{Introduction}

The share of air flight control device wing aileron, elevator, rudder control of the main control device (Primary control system) and secondary day personal flap, spoiler, leading edge flap control of a secondary control device (Secondary control system), they are divided into domestic demand, despite the abundance of technology received recognition in the civil aircraft market, has not been adopted. Medium-class business jet existing parts of the aircraft wing flaps protruding actuators have been called for air resistance and fuel economy. In this study, the protruding parts of an aircraft wing flaps actuators (aileron actuator) mounted inside the wing to remove the protruding part, and the resulting increase in air resistance and fuel economy were targeted. In this study, the wings are mounted inside the actuator system in order to meet the requirements for the design and kinematic analysis of aileron (kinematic motion system) and structural analysis to ensure the structural safety through the analysis results are presented. Kinematic motion analysis program by Sim Designer acting on each joint of aileron force and torque aileron requirements for information corresponding to the conditions that were identified, based to identify the characteristics of each part and the structural basis of this analysis using ABAQUS 6.5 model was developed separately by each working on structural analysis, structural characteristics and performance and forecasts were performed. In addition, components of the safety margin for hydraulic components were confirmed by checking the structural safety.

\section{Kinematic Motion Analysis}

\subsection{Fatigue Prediction Analysis}

The static and cyclic stress-strain curves are modified by the local plastic strain as a effect of material hardening. Specifically, analytical expressions to describe material behavior have been adapted for the implementation into the software FEMFAT v4.6 where local SN-curves are used for linear damage accumulation according Palmgren-Miner's rule. The estimate the simulation number of cycles, We used FEMFAT v4.6 with a high diagram -admissible amplitude by given mean for high cycle fatigue with bending influence relative stress gradient (bending $\chi^{\prime}=2 / b$ ).

$$
f_{\text {genDurance }}=1+\frac{\left(\sigma_{\text {altben }} / \sigma_{\text {altTC }}-1\right)}{(2 / b)^{v}} \chi^{\prime v}
$$

The construction of High diagram calculates the fatigue life of a part under constant amplitude oscillatory loading assuming the stress range controls fatigue life. The Stress-Life method is the Wohler, or S-N diagram, 
where a suitable structural stress, $\mathrm{S}$ (or strain or stress intensity factor) shown schematically for two materials [1]. The S-N diagram plots nominal stress amplitude $\mathrm{S}$ versus cycles to failure N. Rainflow cycle counting is used together with Palmgren-Miner's accumulated damage rule to process variable amplitude loading. In this model it is assumed that the damage on the structures per load cycle is constant at a given stress range and equal. The total damage accumulated during $\mathrm{N}$ cycles of amplitude $S_{a_{i}}$ is given by:

$$
d \delta=\sum_{i=0}^{n-1} \delta_{i} \text { where, } \delta_{i}=\frac{1}{K_{s}} \cdot S_{a_{i}}^{b}
$$

or

$$
d \delta=\frac{1}{K_{s}} \sum_{i=0}^{n-1} S_{a_{i}}^{b}
$$

The accumulated damage $d \delta$ is independent of the sequence in which stress will occur. According to Miner's rule, fatigue failure occurs if total damage $S_{a_{i}}>$ $d \delta$, where $d \delta$ is the critical cumulative damage, which is often taken as 1 . Letting $S_{a_{i}}=d \delta$, the basic damage expression of equation can be expresses in terms of time to failure [2].

\subsection{Mechanism System}

In the generic fighter of aileron example discussed in this paper, linear models will be used. This is not a requisite, but for the analysis based on non-linear models, more detailed information and motion algorithm. The linear actuators of mechanism can be either hydraulic rams or electric spindle devices. The aileron actuator motionbases generally utilize a mechanism known's as the Stwart Platform or "hexapod", which was originally proposed for a base-frame, six actuator legs (the jacks).

This method can be applied to both the gravitational forces and the aerodynamic load and gravitational forces categories [3]. The positioning of the links and joints are not changed within the analysis, because of the nature of the design synthesis performed on the mechanism. By changing the lengths of members or moving the links or joints, the desired motion for morphing the wing may no longer be achievable. Aileron's system as shown in the 3D model is composed of the larger piston, bell crank, clevis, stroke and flap in Figure 1. By using kinematic motion system analysis, all of the above free design variable and constraints can be combined to yield the most architecture aileron actuator of the four major parts. This is part of joint connecting the four joint. For simplified system analysis, in this point unnecessary pin were also removed. This method can be applied to both the gravitational forces and the aerodynamic load and gravi- tational forces categories for aileron mechanism in Figure 2.

Aileron mechanism have moved up the wing when the maximum angle of $19^{\circ}$ (TEU $19^{\circ}$ ), went down to below $11^{\circ}$ (TED $11^{\circ}$ ) at Casel and when the wings moved up $24^{\circ}$ (TEU $24^{\circ}$ ), went down to below $16^{\circ}$ (TED $16^{\circ}$ ) Case 2 a time were compared. The rated pressure of the pressure piston (rated pressure) $2775 \mathrm{psi}$, the maximum pressure $3000 \mathrm{psi}$ applied when compared in each case. The motion analysis represented a Sim Design ${ }^{@}$ and, Adams@; program. See Table 1.

\subsection{Structural Analysis}

The structural analysis model can be divided into three. The piston rod, bellcrank, stroke is these three different parts. The results of kinematic motion analysis were used for the structural analysis based on data that the load applied to each part. The static pressure range because it

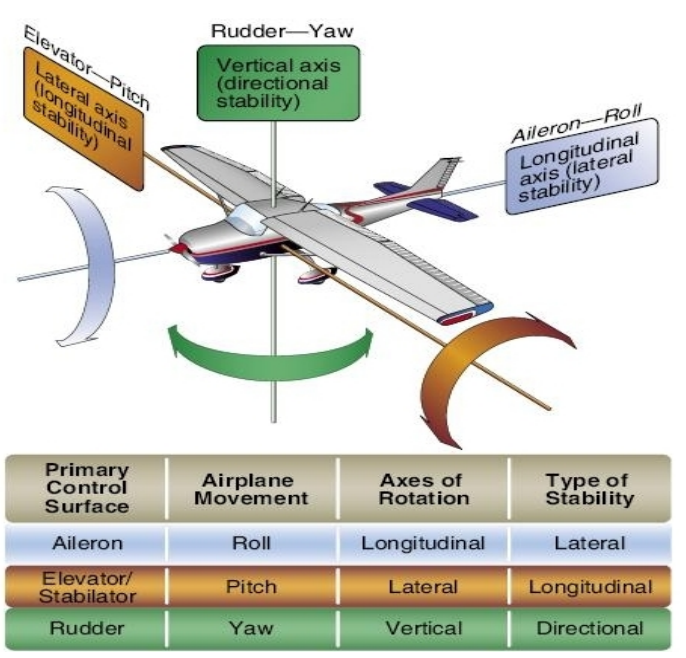

Figure 1. Aircraft control system movement.

Table 1. Kinematic motion analysis in each case.

\begin{tabular}{ccc}
\hline Case & Aileron Angle & Pressure (psi) \\
\hline \multirow{3}{*}{ Case1 } & TEU 19 & 2775 \\
& & 3000 \\
& & 2775 \\
& & 3000 \\
TED 11 & & 2775 \\
& & 3000 \\
& & 2775 \\
& & 3000 \\
\hline
\end{tabular}




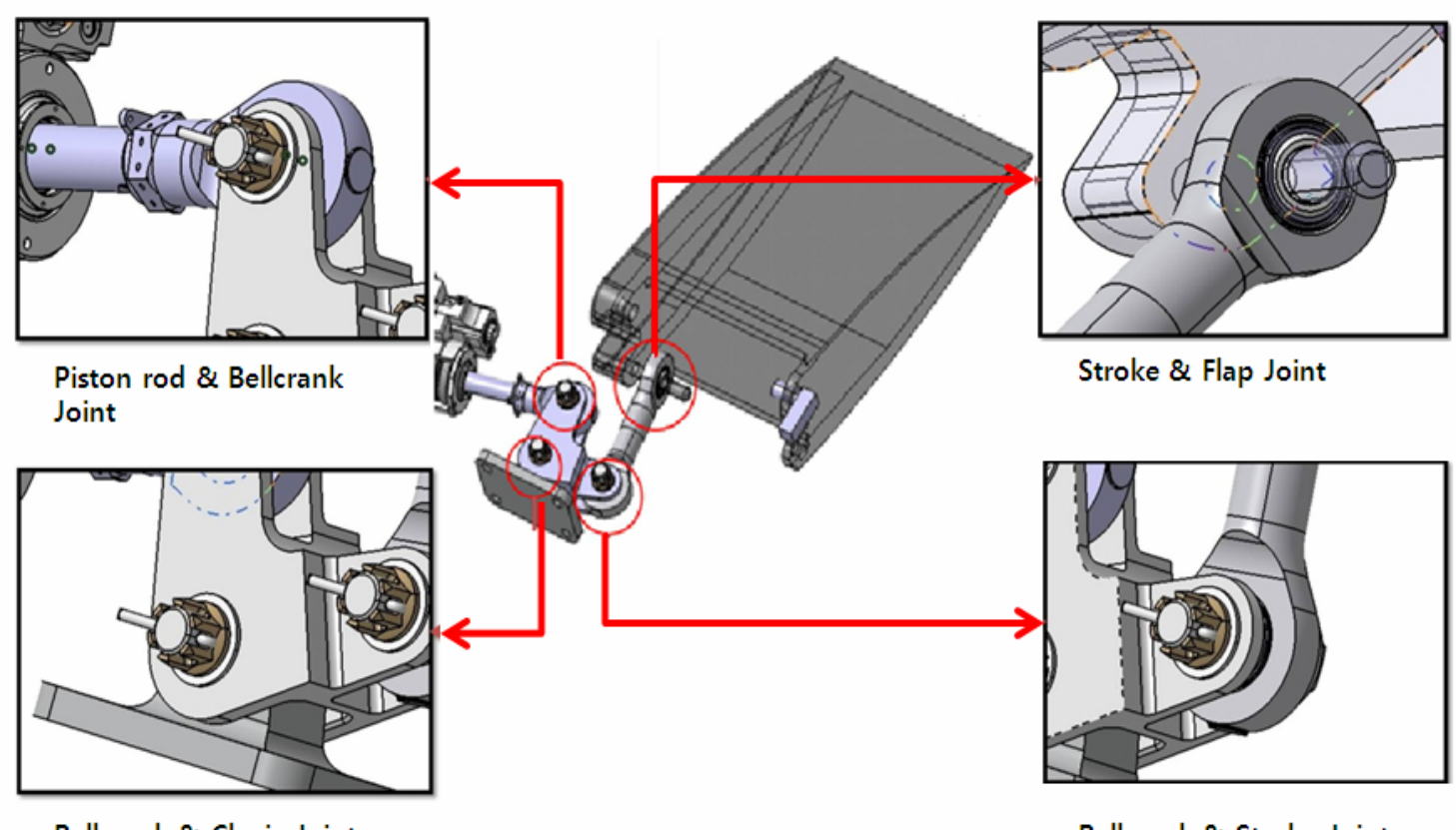

Bellcrank \& Clevis Joint

Bellcrank \& Stroke Joint

Figure 2. Connection composition and joint mechanism.

contains the maximum pressure in the range of a maximum pressure of 3000 psi was the result of applying the data. Case 1 in Table 2 and Case 2 in Table 3 also occurs in the value of the force and torque limit value because they are included within the scope of Case 2 is a TEU 24 - TED $16^{\circ}$ and in the context of structural analysis was carried out. The pressure of piston can be used the maximum pressure 3000 psi. Each model defines a material density as well as linear, elastic isotropic values of modulus of elasticity, and Poisson's ratio. As with the real constants sets, the first tentative designs are modeled after the second generation model $[4,5]$. The materials property include stainless steel (AMS5862 15-5PH) was applied, element type the Tetra mesh (C3D4) were used for ABAQUS 5.7 ${ }^{@}$.

\section{Results of FE Analysis}

\subsection{Results of FE Structural Analysis}

Table 3 shows the result of FE analysis in each part. The results of margin of safety for bell crank (TED $16^{\circ}$ ) and (TED $24^{\circ}$ ) with this final design are 0.434 and 0.429 when the load is estimated to be insufficient to withstand in Figure 3. Bell crank joint connection with the piston rod in the most stress and displacement results showed values of the angle did not differ significantly [6]. The stroke is associated with the bell crank joint was the most stress and displacement. However, the resulting values were different angle, TEU $24^{\circ}$ at a TED $16^{\circ}$ greater than the stress and displacement angles seen representing the larger part that the recipient can know the load is greater in Figure 4 of piston, and Figure 5 of stroke.

Table 2. The results of kinematic motion analysis in case 1.

\begin{tabular}{|c|c|c|c|c|c|}
\hline \multirow[b]{2}{*}{ Joint } & \multirow{2}{*}{$\begin{array}{l}\text { Pressure } \\
\text { (psi) }\end{array}$} & \multicolumn{2}{|c|}{ TED $11^{\circ}$} & \multicolumn{2}{|c|}{ TEU $19^{\circ}$} \\
\hline & & $\begin{array}{l}\text { Force } \\
(\mathrm{N})\end{array}$ & $\begin{array}{l}\text { Torque } \\
\text { (in-lb) }\end{array}$ & $\begin{array}{c}\text { Force } \\
(\mathrm{N})\end{array}$ & $\begin{array}{l}\text { Torque } \\
\text { (in-lb) }\end{array}$ \\
\hline \multirow{2}{*}{$\begin{array}{c}\text { Piston \& } \\
\text { Bell crank }\end{array}$} & 2775 & 37936 & 2929.2 & 37936 & 2929.2 \\
\hline & 3000 & 41012 & 3166.8 & 41012 & 3166.8 \\
\hline $\begin{array}{c}\text { Bell crank } \\
\& \text { Clevis }\end{array}$ & 2775 & 54983 & 8222.8 & 67412 & 11340.4 \\
\hline
\end{tabular}

Table 3. The results of kinematic motion analysis in case 2 .

\begin{tabular}{cccccc}
\hline & & \multicolumn{2}{c}{ TED $16^{\circ}$} & \multicolumn{2}{c}{ TEU 24 } \\
Joint & $\begin{array}{c}\text { Pressure } \\
\text { (psi) }\end{array}$ & $\begin{array}{c}\text { Force } \\
(\mathrm{N})\end{array}$ & $\begin{array}{c}\text { Torque } \\
(\text { in-lb) }\end{array}$ & $\begin{array}{c}\text { Force } \\
(\mathrm{N})\end{array}$ & Torque (in-lb) \\
\hline Piston \& & 2775 & 37936 & 2929.2 & 37936 & 2929.2 \\
Bell crank & 3000 & 41012 & 3166.8 & 41012 & 3166.8 \\
Bell crank & 2775 & 56979 & 8497.3 & 79347 & 14713.8 \\
\& Clevis & 3000 & 61600 & 9186.8 & 85781 & 15907.1 \\
Bell crank & 2775 & 39473 & 3269.7 & 61413 & 5081.8 \\
\& Stroke & 3000 & 42674 & 3534.9 & 66392 & 5493.8 \\
Stroke \& & 2775 & 39473 & 3031.2 & 61413 & 4717.5 \\
Flap & 3000 & 42674 & 3094.4 & 66392 & 5100.0 \\
\hline
\end{tabular}

The stroke, but also belong within the range of margin of safety is sufficient to withstand the loads are evaluated. When applied to the piston displacement amount 3000 
psi maximum pressure $0.105 \mathrm{~mm}$, Von-Mises Stresses 274.6 Mpa 2.446 calculated by the margin of safety is sufficient to withstand the loads are evaluated [7,8].

\subsection{Results of Fatigue Analysis}

By a standard fatigue life analysis with FEMFAT the following influences are considered: Influence of the relative stress gradient to consider notch support effects Mean stress influence Modification of high diagram by calculating a notch ultimate strength statistic influence. The calculation for the fatigue life presented in this paragraph deviates in some important aspects from standard calculations for fatigue life. Prior to the fatigue analysis a forming simulation with FEMFAT v4.6 has been made [9]. The results of this simulation have been mapped onto a new mesh better suitable for a structural analysis in Figure 6. The structural analysis delivers the additional stresses of each load cycle. Therefore following data is included additional to a standard calculation in the model. The second point needs special attention here because the residual stresses are very high. Usually it is assumed that the high stresses resulting from manufacturing are somehow relieved in the first load cycles. However, such an effect cannot be simulated with a program on the basis of continuum mechanics in Figure 7.

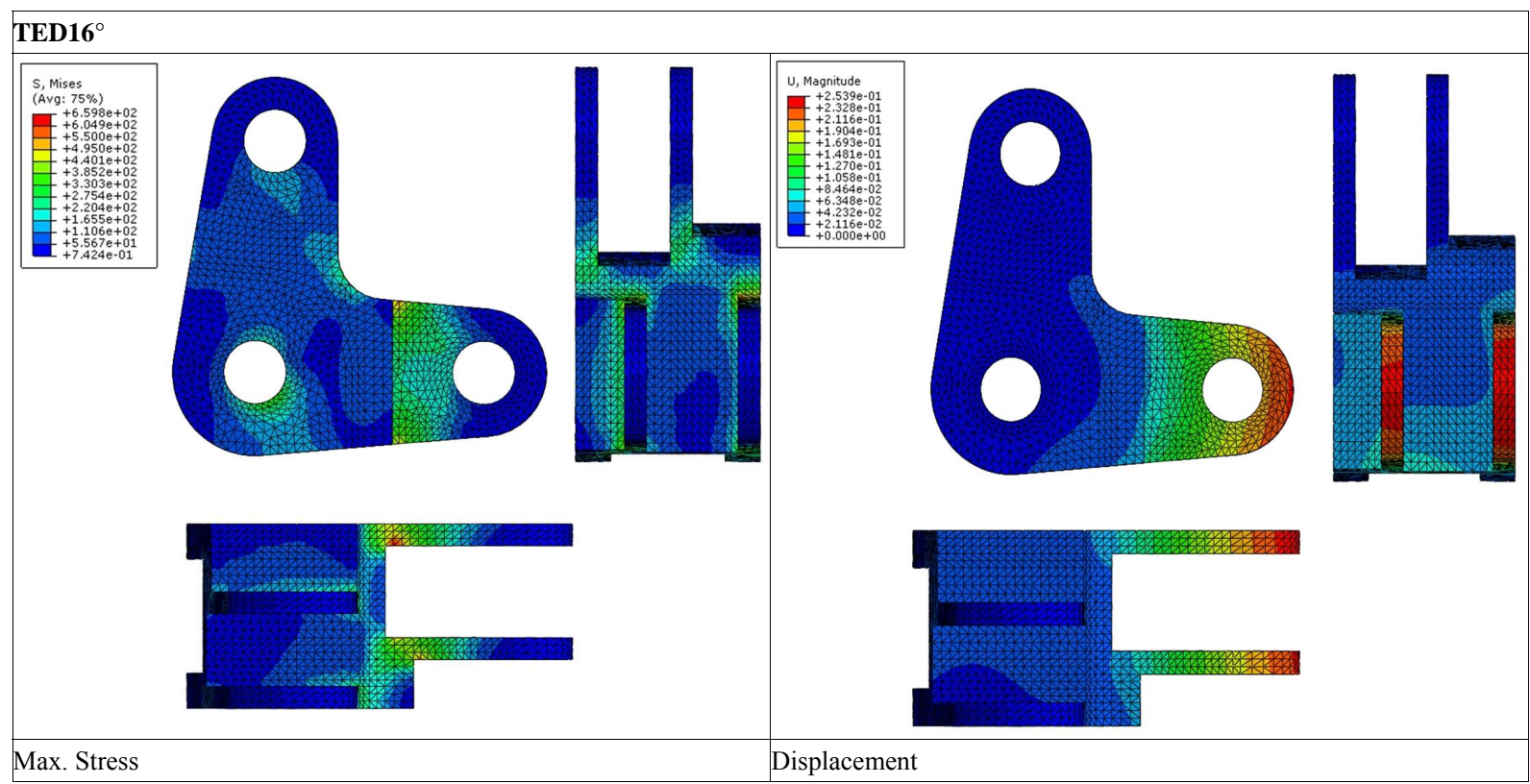

(a)

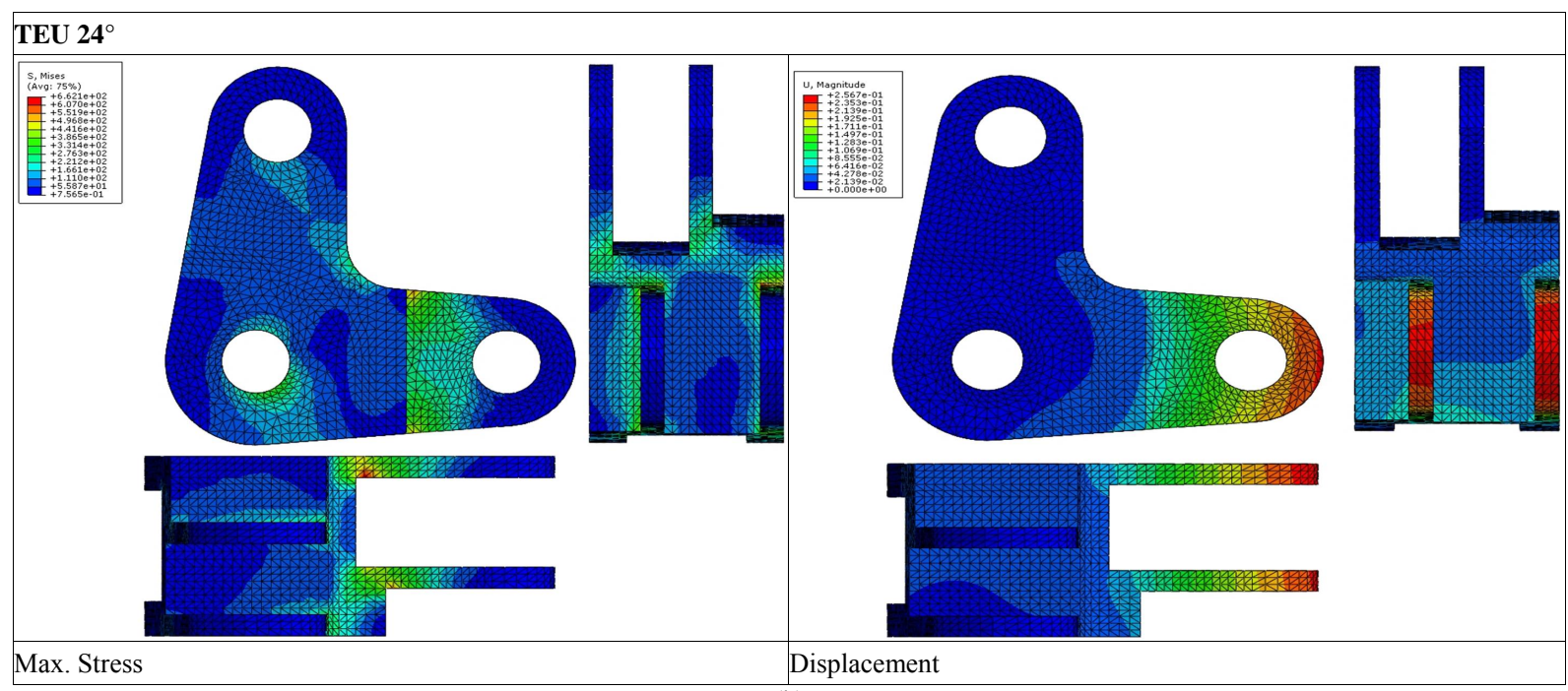

(b)

Figure 3. FE Analysis of aileron bellcrank in TED $16^{\circ}$ and bellcrank in TED $24^{\circ}$ 


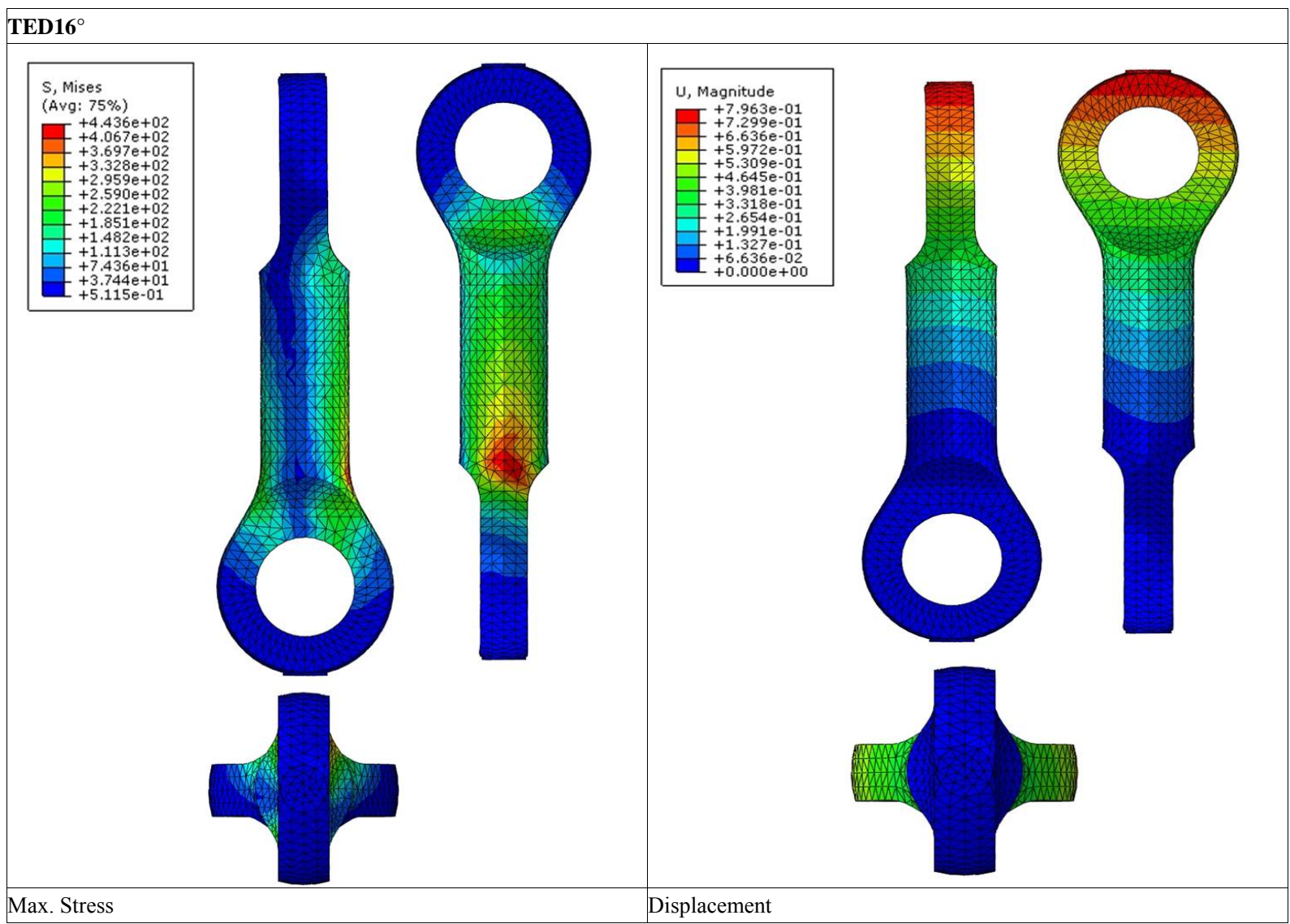

Figure 4. FE Analysis of piston in TED $16^{\circ}$.

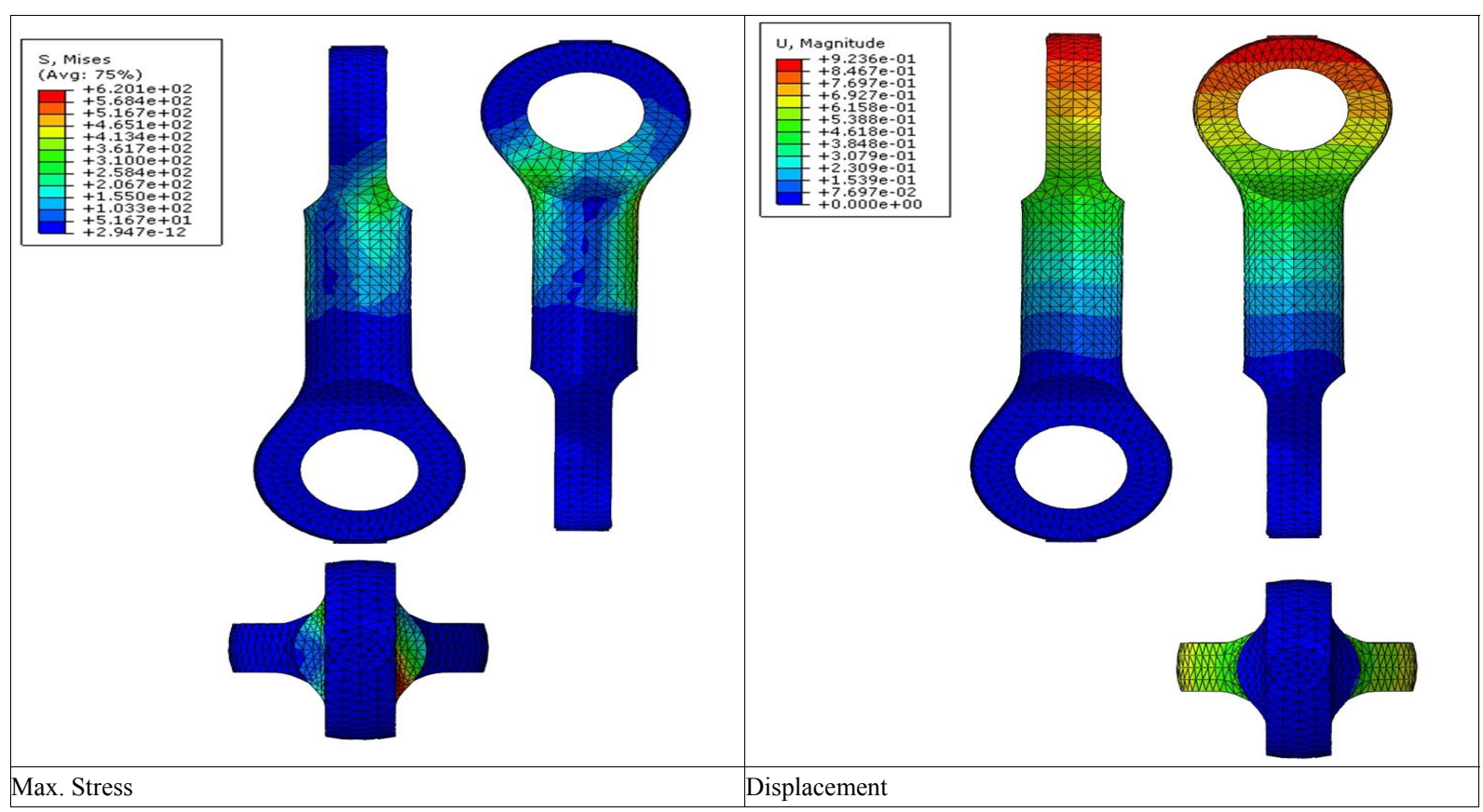

Figure 5. FE Analysis of Stroke in TED $24^{\circ}$ 


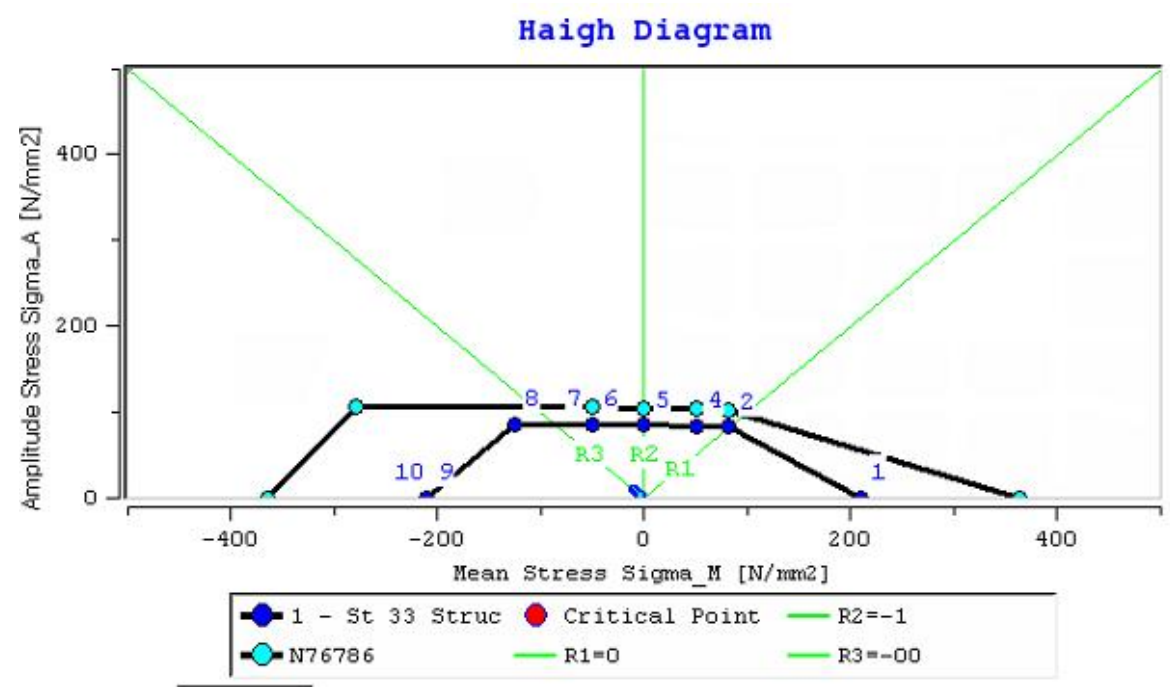

Figure 6. Haigh diagram of stroke in TED 24

Table 4. Results of FE Fatigue analysis.

\begin{tabular}{cccccc}
\hline & Pressure (psi) & Angle & $\begin{array}{c}\text { Mean. } \\
\text { Stress (Mpa) }\end{array}$ & $\begin{array}{c}\text { Margin of } \\
\text { Safety (N.S.) }\end{array}$ & $\begin{array}{c}\text { Max. } \\
\text { Displacement (mm) }\end{array}$ \\
\hline \multirow{3}{*}{ Bell crank } & 3000 & $16^{\circ}$ & 659.8 & 0.434 & 0.253 \\
& & $24^{\circ}$ & 662.1 & 0.429 & 0.256 \\
Stroke & 3000 & $16^{\circ}$ & 443.6 & 1.133 & 0.796 \\
& \multirow{2}{*}{ Piston } & $24^{\circ}$ & 620.1 & 0.527 & 0.923 \\
\hline
\end{tabular}

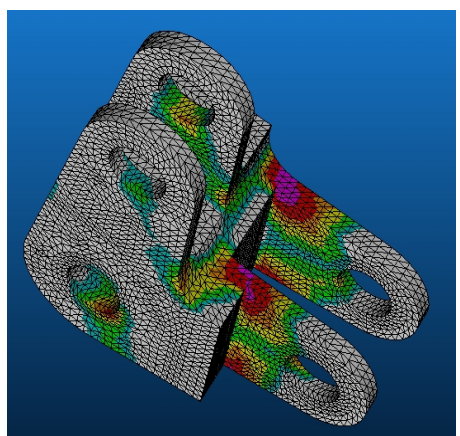

(a)

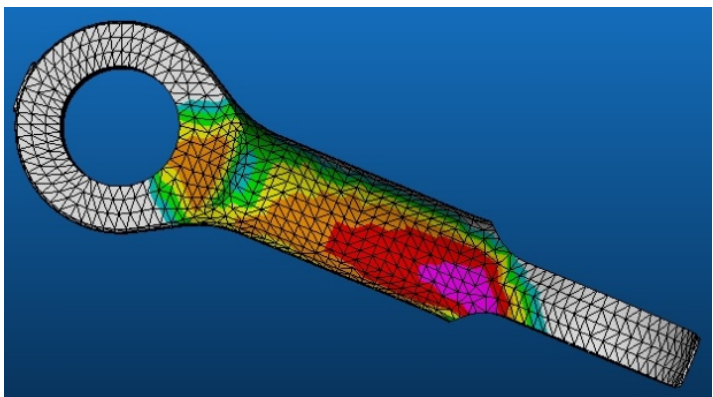

(b)

Figure 7. Results of fatigue analysis of stroke and bell crank (a) After results of fatigue analysis of bell crank (b) After results of fatigue analysis of stroke.

To account for this effect precisely further measurements are necessary, here the mean stresses have been halved. Inclusion of the plastic equivalent strain according Masendorf shows a clear influence on the results: without it the computed fatigue life is 1,44 million load cycles, with it 1.752 million load cycles.

This research to improve the endurance life of stroke required for the life cycle design, analysis and testing for the integration of these technologies and secure source technology to derive prototype has been applied, the fol- lowing were able to obtain useful results. The FE results, designed and built by the stroke was able to reduce the time and cost. The endurance life cycle how to establish durable, and is designed to help improve productivity, and to be tested.

Therefore the fatigue life calculated is lower than the fatigue life measured. By generation of new materials for different plastic equivalent strains according to the material's property the fatigue life result can be improved once again. See Table 4. 


\section{Conclusions and Discussion}

In this paper, FE structural analysis and Fatigue prediction analysis of the flight control actuators for capacity are presented. Aileron actuator 3 main parts of the piston, bell crank, divided by the stroke of 3D analysis model was developed. Verification calculations prove the model developed in Sim Design and ABAQUS 5.7 and FEMFAT 4.6 as being accurate. FE structural analysis and Fatigue prediction analysis performed on the basis of stress distribution and the amount of displacement could be predicted. Analysis of aileron actuator model experiments and simulations to create the actual equipment that would reduce costs and time are considered. In addition, through the optimization of the analytical model analysis time and results can be predicted more accurately than is believed to be Through comparison of the test results and analysis, aileron actuator of the results for the endurance can secure the trust stroke, piston, bell crank, depth due to the number of design guidelines to provide for the endurance in life expectancy. By including the results from process simulations, significant improvements regarding correlation of fatigue life predictions to test results can be achieved. Among the biggest effects are influences from material. Methods and interfaces have been implemented in FEMFAT to account for the manufacturing influences. Benefits from applying these new features are high at reasonable efforts because results from process simulation are usually available during concurrent engineering.

\section{Acknowledgment}

This research was supported by the Korea Institute for Advancement of Technology, supporting fund of Honam Leading Industry Office in 2013 by grant No. 2013-0114.

\section{REFERENCES}

[1] B. S. Kim et al., "A Numerical Analysis of the Dimensional Stability of the Plastic Composites Using a Thermoviscoelastic Composite Using a Thermoviscoelastic," Journal of Composite Material, Vol. 36, No. 20, 2002, pp. 2389-2403. doi:10.1177/0021998302036020882

[2] B. S. Kim et al., "Dimensional Stability Analysis of Themoviscoelastic for EMI Shielding Using Melamine-Formaldehyde Composite Materials," Int's Conference on Advances in Structural Engineering and Mechanics (ASEM02), 2002.

[3] T. K. Ahn and C. D. Mote Jr., "Monitoring and Preventing the Kick-off during Cutting," California Cedar Product Co., 1996.

[4] M. K. Choi and E. K. Kim, "Ultra-Thinned Si Wafer Processing for Wafer Level 3D Packaging," Journal of KWJS, Vol. 26, No. 1, 2008, pp. 12-16.

[5] S. A. Nasar, "Linear Electric Motors: Theory, Design, and Pratical Applications," 2008, Prentice-Hall. Inc.

[6] P. C. Sen, "On Linear Synchronous Motor (LSM) for High Speed Propulsion," IEEE Transaction on Magnetics, Vol. Mag-11, No. 5, 1975, pp. 1484-1486. doi:10.1109/TMAG.1975.1058873

[7] C. W. Jun, K.Y. Park and Q. S. Kang, "On the Static Test of Aileron Control System for a Basic Trainer," KSAS journal, Vol. 28, No. 3, 2000, pp. 150-155.

[8] S. S. Kim, Y. J. Kang and K. I. Lee, "Experimental Verification of Flexible Multibody Dynamic Simulations for A Rotating Beam," KSME International Journal, Vol. 26, No. 2, 2002, pp. 267-274.

[9] I. H. Moon and Y. K. Huang, "Evaluation of a Wafer Transportation Speed for Propulsion Nozzle Array on Air Levitation System," Journal of Mechanical Science and Technology (KSME Int. J.), Vol. 20, No. 9, 2006, pp. 1492-1501. 